\title{
A Rare Case of Extramedullary Plasmacytoma Presenting as Large Abdominal Mass
}

\author{
Dieter Brummund $^{1}$, Benjamin Sinyor ${ }^{1}$ \\ 1. Surgery, Aventura Hospital and Medical Center, Aventura, USA
}

Corresponding author: Dieter Brummund, dieter.brummund@hcahealthcare.com

\begin{abstract}
A 79-year-old female with a past medical history of multiple myeloma, diabetes mellitus and chronic kidney disease presented to the hospital with generalized weakness. The patient was found to have a firm abdominal wall mass with no underlying skin changes or drainage on physical examination. Computerized tomography of the abdomen and pelvis without contrast revealed a large mass-like structure in the anterior abdominal wall in the subcutaneous region extending into the abdomen through the mesentery with juxtaposition and partial involvement of the left hepatic lobe and distal stomach. Solitary extramedullary plasmacytomas are extremely rare tumors that occur outside of the bone marrow in the absence of systemic involvement. This case reports details the finding of an extramedullary plasmacytomas, which accounts for less than $5 \%$ of plasma cell neoplasms.
\end{abstract}

Categories: Pathology, General Surgery, Anatomy

Keywords: plasmacytoma, mass, abdomen, pathology, surgery, plasma

\section{Introduction}

Out of all the hematologic malignancies in the United States, multiple myeloma accounts for approximately $17 \%$ [1]. This equates to approximately $1 \%$ of all cancers, with an annual incidence of approximately $4-5$ per 100,000 [2]. Multiple myeloma is understood as a disease of older adults, with a slightly higher incidence in African Americans compared to Caucasians, and a lower risk of incidence in those of Asian and Hispanic descent [3]. A slight familial risk has also been documented, demonstrating a higher risk in patients who have a first degree relative with the disease [4].

Extramedullary involvement is an uncommon occurrence in multiple myeloma with studies citing findings of extramedullary plasmacytomas (EMP) in $7 \%$ at diagnosis, and $6 \%$ incidence later $[5,6]$. Extramedullary plasmacytomas generally involve the liver, spleen, and hematopoietic tissues reflecting their lymphoid origin. The presence of extramedullary disease both at diagnosis and later has been associated with poor outcomes $[7,8]$. Diagnosis is confirmed by histopathology demonstrating plasma cell origin and immunohistochemistry with CD138+ staining. Treatment involves chemotherapy such as bortezomib, radiation, novel biologics, and bone marrow transplant.

Received 07/04/2020

Review began 07/05/2020 Review ended 07/30/2020 Published 08/14/2020

\section{() Copyright 2020}

Brummund et al. This is an open access article distributed under the terms of the Creative Commons Attribution License CC-BY 4.0., which permits unrestricted use, distribution, and reproduction in any medium, provided the original author and source are credited.

\section{Case Presentation}

We present a case of a 79-year-old female with a chief complaint of abdominal pain ongoing for two months. The pain was described as ongoing, increasing in intensity, non-radiating, generalized, and diffuse with no other associated symptoms. She also complained of generalized weakness during this time. The patient did not report fever, chills, weight loss, night sweats, headache, chest pain, dysuria, melena, diarrhea, or constipation. She reported a medical history of multiple myeloma diagnosed 2 years ago and currently in remission, chronic kidney disease, diabetes, and an episode of complicated sigmoid diverticulitis. She reported a surgical history of subtotal colectomy with ileorectal anastamotic reconscrution, ventral hernia repair and left nephrectomy.

The physical exam demonstrated an abdominal wall mass that was firm with no overlying skin changes or drainage.

Blood work found a leukocytosis of 15,800 leukocytes per microliter and a hemoglobin of $8.8 \mathrm{~g} / \mathrm{dL}$. Liver function was preserved with an alkaline phosphatase of $128 \mathrm{U} / \mathrm{L}$, alanine transferase and aspartate transferase of $15 \mathrm{U} / \mathrm{L}$ and $23 \mathrm{U} / \mathrm{L}$, respectively, total protein of $6.7 \mathrm{~g} / \mathrm{dL}$, and albumin of $3.4 \mathrm{~g} / \mathrm{dL}$ was done given the hepatic involvement seen on tomography.

Computed Tomography of the abdomen and pelvis without IV contrast reported a large mass-like structure was seen in the anterior abdominal wall in the subcutaneous region extending into the abdomen and through the mesentery with juxtaposition and partial involvement of the left hepatic lobe and distal stomach. The mass measured $17.9 \times 15.9 \times 8.5 \mathrm{~cm}$ and was of soft tissue density with circumscribed margins, 38 hounsfield units, without adjacent inflammatory changes. Additional masses were seen abutting the 


\section{Cureus}

posterior right hepatic lobe and spleen, and there was a prominent mass in the mid-mesentery (figure 1,2).

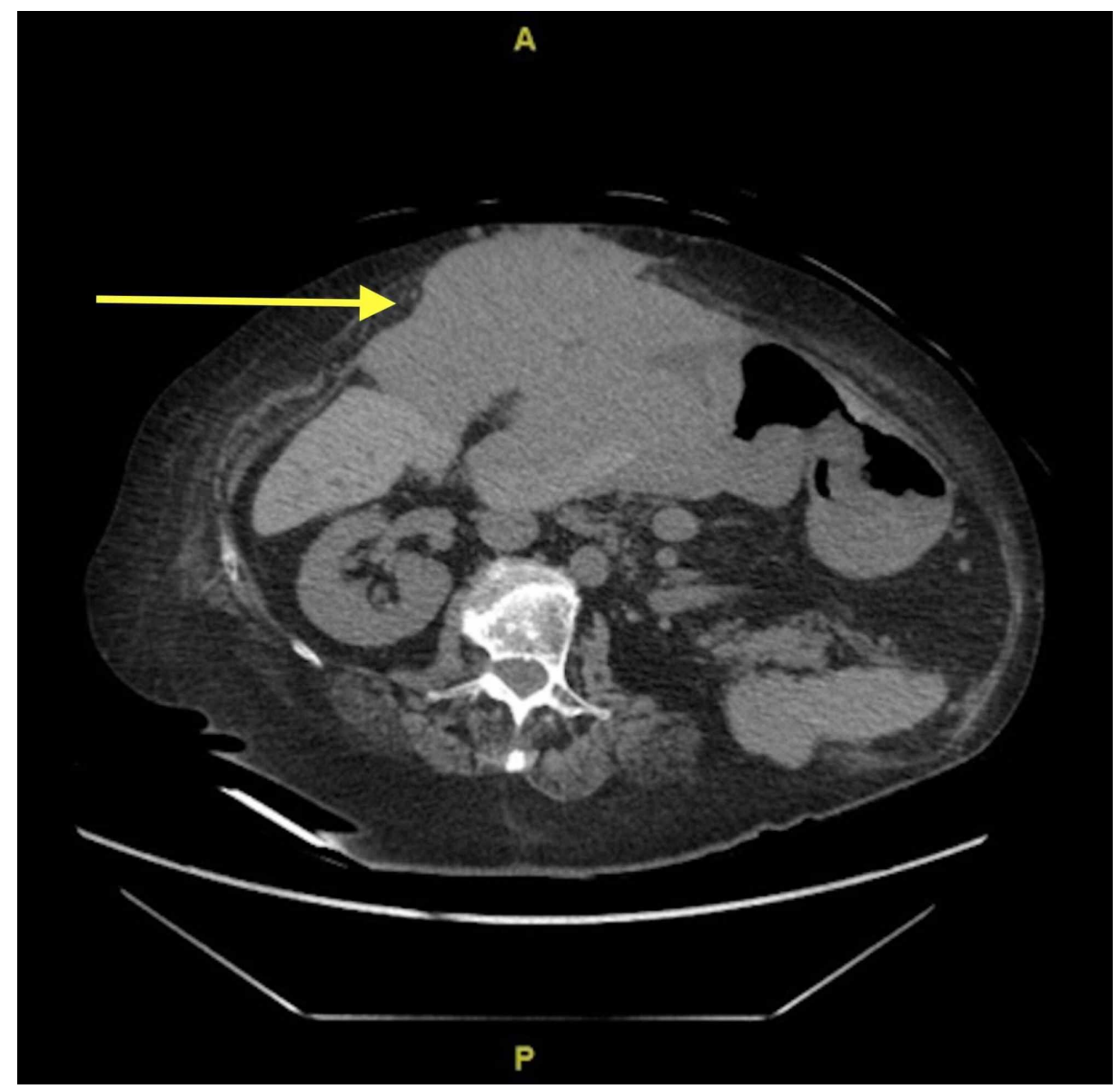

FIGURE 1: Transverse CT with IV contrast showing a soft tissue mass abutting the anterior liver, infiltrating the anterior abdominal wall and involving the stomach 


\section{Cureus}

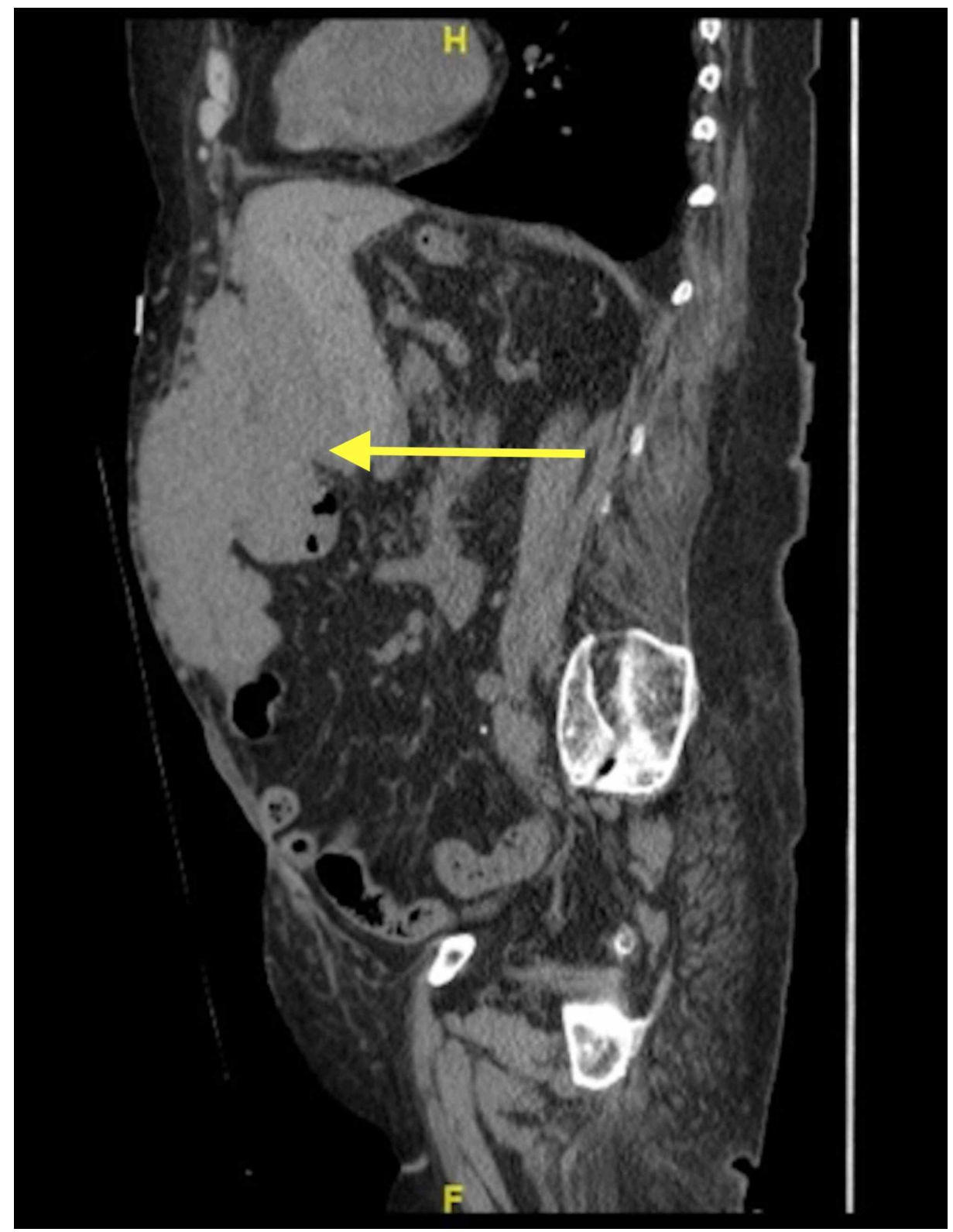

FIGURE 2: Sagittal CT with IV contrast showing a soft tissue abutting anterior liver, and infiltrating anterior abdominal wall.

A core needle biopsy performed by interventional radiology confirmed the presence of monoclonal CD138+ plasmacytoid cells consistent with a plasma cell neoplasm.

Medical oncology was consulted and arranged for outpatient follow up with positron emission tomography to evaluate for active areas of relapse and to begin a triple therapy regimen with daratumumab, pomalidomide and dexamethasone.

\section{Discussion}

Multiple myeloma (MM) is a malignant process that involves a neoplastic proliferation of plasma cells characterized by bone marrow involvement, extensive skeletal destruction, renal dysfunction, and elevated total serum protein levels. As a systemic illness, this disease typically presents with systemic symptoms including anemia, bone pain, elevated renal function tests, and weight loss in the majority of patients.

Extramedullary involvement is uncommon, with studies citing findings of extramedullary plasmacytomas (EMP) of 7\% at diagnosis, and 6\% incidence later in the course of multiple myeloma [6]. EM involvement has been shown to have less favorable outcomes and shorter overall survival [5,6,7,8]. Extramedullary plasmacytomas generally involve the liver, spleen, and hematopoietic tissues reflecting their lymphoid origin. Postulated mechanisms of extramedullary spread involve decreased expression of cell to cell 
A subtype of extramedullary disease is cutaneous multiple myeloma and has been associated with particularly aggressive biological behavior and short survival [9]. Common cutaneous manifestations of MM include leukocytoclastic vasculitis, pyoderma gangrenosum, and vesiculobullous disorders.

Diagnosis of extramedullary plasmaycotoma is confirmed through needle biopsy of the affected tissue with histopathology demonstrating plasmacytoid cells and immunohistochemistry staining for CD138+.

As the presence of extramedullary plasmacytomas in multiple myeloma, both at diagnosis and later during the disease course, has been associated with poor outcomes, extramedullary recurrence warrants an escalation of therapy with proteasome inhibitor therapy found superior to that of thalidomide alone [10]. In certain younger patients, aggressive chemotherapy followed by bone marrow transplant has resulted in improved outcomes not seen with conventional treatment of recurrent extramedullary disease [8].

In our report, we provide evidence of the need to consider a broad differential and to evaluate for recurrence when assessing solid masses in the setting of known hematologic malignancies.

\section{Conclusions}

The presence of an extramedullary mass is particularly concerning for patient prognosis in the setting of known hematologic malignancy. Consideration of extramedullary plasmacytoma in patients who present with subcutaneous masses demonstrated on exam and with a history of multiple myeloma should raise a high index of suspicion for recurrence and treatment failure. The findings warrant prompt subsequent histologic and immunohistory chemistry confirmation with biopsy, genotyping and escalation to 2nd and 3rd line agents in treatment. Further studies are necessary to determine the optimal course of treatment for patients with this particular presentation given the known and previously documented poor prognosis.

\section{Additional Information}

\section{Disclosures}

Human subjects: Consent was obtained by all participants in this study. Conflicts of interest: In compliance with the ICMJE uniform disclosure form, all authors declare the following: Payment/services info: This research was supported (in whole or in part) by HCA Healthcare and/or an HCA Healthcare affiliated entity. The views expressed in this publication represent those of the author(s) and do not necessarily represent the official views of HCA Healthcare or any of its affiliated entities. Financial relationships: All authors have declared that they have no financial relationships at present or within the previous three years with any organizations that might have an interest in the submitted work. Other relationships: All authors have declared that there are no other relationships or activities that could appear to have influenced the submitted work.

\section{References}

1. Siegel RL, Miller KD, Jemal A: Cancer statistics 2019. CA Cancer J Clin. 2019, 69:7-34. 10.3322/caac.21551

2. Kyle RA, Therneau TM, Rajkumar SV, Larson DR, Plevak MF, Melton III LJ : Incidence of multiple myeloma in Olmsted County, Minnesota: trend over 6 decades. Cancer. 2004,101:2667-2674. 10.1002/cncr.20652

3. Kyle RA., Gertz MA, Witzig TE, et al : Review of 1027 patients with newly diagnosed multiple myeloma . Mayo Clin Proc . 2003, 78:21-33. 10.4065/78.1.21

4. Lynch HT, Sanger WG, Pirruccello S, Quinn-Laquer B, Weisenburger DD: Familial multiple myeloma: a family study and review of the literature. JNCI. 2001, 93:1479-1483. 10.1093/jnci/93.19.1479

5. Cao D, Li L, Liu L, et al.: Solitary extramedullary plasmacytoma of the adrenal gland: a rare case report with review of the literature. Int I Clin Exp Pathol. 2014, 7:9072-9075.

6. Schols, SE, Tick LL: Recurrent extramedullary plasmacytoma in asymptomatic multiple myeloma: a case report. J Med Case Rep. 2015, 9:1-6. 10.1186/s13256-014-0506-3

7. Mendenhall WM, Mendenhall CM, Mendenhall N: Solitary plasmacytoma of bone and soft tissues . Am J Otolaryngol. 2003, 24:395-399. 10.1016/S0196-0709(03)00092-9

8. Bladé J, de Larrea CF, Rosiñol L, Cibeira MT, Jiménez R, Powles R: Soft-tissue plasmacytomas in multiple myeloma: incidence, mechanisms of extramedullary spread, and treatment approach. J Clin Oncol. 2011, 29:3805-3812. 10.1200/JCO.2011.34.9290

9. Malysz J, Talamo G, Zhu J, et al.: Cutaneous involvement in multiple myeloma (MM): A case series with clinicopathologic correlation. J Am Acad Dermatol. 2016, 74:878-884. 10.1016/j.jaad.2015.12.028

10. Varettoni M, Corso A, Pica G, Mangiacavalli S, Pascutto C, Lazzarino M: Incidence, presenting features and outcome of extramedullary disease in multiple myeloma: a longitudinal study on 1003 consecutive patients. Ann Oncol. 2010, 21:325-330. 10.1093/annonc/mdp329 